\title{
Private and Public Investment Growth: Macroeconomic Expectations and Fiscal Policy Uncertainty
}

\author{
Rexford Abaidoo ${ }^{1}$ \\ ${ }^{1}$ School of Business and Technology, University of Maryland Eastern Shore, USA \\ Correspondence: Rexford Abaidoo, Kiah Hall, Room 2117-D, University of Maryland Eastern Shore, Princess \\ Anne Maryland, 21853. USA. Tel: 410-621-3380. Email: rabaidoo@umes.edu
}

Received: November 7, 2013

Accepted: November 19, 2013

Online Published: December 23, 2013

doi: 10.5539/ibr.v7n1p116

URL: http://dx.doi.org/10.5539/ibr.v7n1p116

\begin{abstract}
This study examines potential disparities in how specific adverse macroeconomic conditions impact variability in US private and public investment growth. Using quarterly time series data spanning the period 1960-2012 and array of econometric procedures such as ARDL-Bound Test technique etc.; effects of specific macroeconomic conditions such as recession and inflation expectations on private and public investment growth are estimated. Our results show that in the short run, only macroeconomic uncertainty and fiscal policy volatility among variables tested, drives significant fluctuations in private investment growth. This study also finds that recession expectations rather augments public investment growth in both the short and the long run; but constrains private investment growth in the long run. Additionally, comparative analysis further show that private investment growth tend to be more susceptible to adverse macroeconomic conditions tested in this study than public investment growth.
\end{abstract}

Keywords: recession expectations, inflation expectations, fiscal policy volatility, ARDL-bound test approach

\section{Introduction}

This study investigates potential disparities in how private and public investment growth conditions respond to, or are impacted by specific macroeconomic conditions. The approach adopted in this empirical study, critically examines trend dynamics associated with each investment growth strand; and how modeled macroeconomic conditions impact such trend. Among other things, the outcome of this empirical inquiry is projected to provide crucial data driven evidence which could augment our understanding of conditions responsible for periodic fluctuations in US private and public investment growth. Empirically verifiable conclusions emanating from this study could also help in reshaping existing policy strategies for tailored macroeconomic policies targeting investment growth stability and economic growth. This study's examination of the behavior of private and public investment growth, in an environment characterized by specific adverse macroeconomic conditions is conducted using proven system of econometric models capable of uncovering such dynamic relationships. A review of the literature focusing on mechanics of investment growth such as Bloom, Bond and Reenen (2007), Le Quan V. (2004) etc. show that investment growth, like most macroeconomic indicators, does not occur in a vacuum; in that, decisions fueling such investments are often shaped or defined by specific prevailing or projected macroeconomic conditions. Thus, the customary view that significant portion of the variability in investment growth, is driven to large extent by prevailing and forecasted macroeconomic conditions is consistent with existing literature. This linkage between macroeconomic conditions and investment growth has been verified by legion of empirical studies focusing on the evolving relationship. Some of the studies verifying this relationship have for instance, concluded that macroeconomic conditions to a greater extent, defines and dictates direction of most investments; and consequently, it's growth trajectory. Specifically, substantial number of such studies (Note 1) have concluded that adverse macroeconomic conditions such as economic uncertainty, fiscal policy volatility, interest rate volatility etc. negatively impact investment growth; whereas favorable macroeconomic conditions characterized by stable and appreciable growth augmenting conditions, elicits significant investment growth.

Studies such as Aizenman and Marion (1999), Moguillansky (2002), which focused primarily on the relationship in question among developing economies, for instance, found a negative relationship between 
private investment growth and several macroeconomic and uncertainty measures. In a related study, Federer (1993) also concluded that macroeconomic uncertainty has significant negative impact on US equipment investment growth. These conclusions, which to some extent captures conditions in both developed and developing economies (as well as others to be discussed in later sections), suggest that apart from known traditional determinants of investment growth such as loan supply, interest rate etc., investment growth dynamics are also inherently defined by prevailing macroeconomic conditions. This conclusion is supported to some extent by recent US economic performance data. For instance, reviewed quarterly historical US investment growth data show that investment growth, tend to contract significantly during periods of economic decline or heightened macroeconomic uncertainty, and rebound during periods characterized by reverse conditions. Again, macroeconomic performance data from the Federal Reserve Economic Database (FRED), also show that US net domestic investment growth, recorded its most significant percentage decline since the 1960s, in 2008 in responds to the recession of 2008. These facts, to some extent supports prevailing view that investment growth, all things being equal, trend with prevailing macroeconomic conditions.

Like most developed and developing economies around the world, the US economy experienced significant decline in structural growth during the recent global economic decline brought about by the 2008 recession. Since this economic episode which negatively impacted key component of GDP growth (consumption, investments etc.), there have deliberate ongoing efforts and measures geared towards accelerating growth among various sectors of the economy. Current macroeconomic data however, suggests these efforts by the federal and state governments have not been entirely successful in putting the economy back on desired economic growth trajectory. Although recent (2013) trends in the real estate sector, the stock market, consumption expenditures, etc. are significantly better compared to trends in periods immediately after the recession of 2008, the same economic data also shows the US economy in general still lag behind macroeconomic conditions that existed prior to the 2008 recession. Domestic investment growth for instance, has not fully recovered from the 2008 economic shock; a condition which this study believes could be attributed to lingering macroeconomic uncertainty and less reliable or informative economic signals. This view that macroeconomic uncertainty could be responsible for constrained US investment growth in recent years is consistent to some degree with projections of rational expectations theory; which predicts rational behavior on the part of the average investor. Existing empirical findings (based on this theory) suggest that in periods of significant macroeconomic perturbations, viability or profitability signals associated with most investment projects become distorted; making it extremely difficult for investors to accurately assess potential viability of projects of interest. In such condition, rational expectation theory project that rational investors whose ultimate goal is to maximize profit utilizing all available information, will often defer on proposed investment projects until they can predict how prevailing conditions will impact such investments. Thus, prevailing and projected macroeconomic conditions to a greater degree defines the extent of investment growth by impacting investor behavior.

\subsection{Theories of Investment Growth: A Succinct Account}

This section provides succinct account of evolving theories formulated to explain investment growth dynamics. The section examines three of the leading theories on dynamics of investment growth. A quick review of these theories show that each theory tend to attribute variability in investment growth to varied factors or conditions in its assessments of factors responsible for investment behavior. Most of the factors or conditions identified by the theories are mainly industry, firm operational specific or demand driven considerations. This study however, as already noted, takes a different approach by focusing on potential effects of specific macroeconomic conditions (expectations and uncertainty) on private and public investment growth. This section analyzes key conclusions of the following investment theories: the Accelerator Principle, the Jorgenson neoclassical theory, and the Tobin-q investment concept which continue to shape our understanding of mechanics of investment performance. Critical assessment of each of these theories with the exception of the Tobin-q investment framework, suggest that each tend to deliberate on specific procedure in explaining investment growth behavior without specifically capturing effects of expectations or external macroeconomic conditions critical to investment performance. For instance, the accelerator principle, posits that investment growth has a linear relationship with changes in output driven consumer confidence and demand; although one could inherently argue for implied effects of uncertain macroeconomic conditions, the framework does not specifically address the condition (i.e., external macroeconomic effects).

The Jorgenson's dynamic model of investment growth which describes optimal investment behavior based on capital stock adjustment flexibility; also seem to suggest that macroeconomic conditions being considered in this 
study might not be that detrimental to investment growth. Although this investment performance formulation has been shown to be attractive because of its capture of user cost of capital, critics still suggests the framework relies too heavily on ad hoc adjustment mechanism imposed to determine the rate of investment growth (Chirinko, 1993). The Jorgenson framework, for instance somehow seem to imply that there should be no "worries" about the future (that is, dire macroeconomic expectations for instance might not impact significantly on investment growth) since firms can adjust capital stock to any change in the environment. The Tobin-Q investment formulation, an investment concept propounded by Tobin J. (1969) on the other hand, argues that the rate of investment (growth) is a function of Q, (Tobin's Q) that is, the ratio of market value of new additional investment to its replacement cost. This investment framework suggests that if $\mathrm{Q}$ is greater than one $(\mathrm{Q}>1)$, then an additional investment by a firm would make economic sense because projected profits generated would exceed the cost of firm's assets. However, if $\mathrm{Q}$ is less than one $(\mathrm{Q}<1)$ then, the potential for losses will serve as disincentive to embark on any investment or engage a firm's assets. Thus, according to this framework, the level of $\mathrm{Q}$ facing firms constitutes the dominant condition determining investment growth dynamics all things being equal.

However, unlike these investment frameworks which continue to spearhead our understanding of investment growth dynamics, this study rather focuses on how public and private components of general US investment growth, respond to specific macroeconomic conditions or external macroeconomic stimuli. This approach does not seek to merely verify whether specific macroeconomic conditions constrain investment growth or otherwise; in that, there is sufficient empirical evidence to that effect already in the present literature. The approach adopted in this study rather verifies potential differences in the magnitude of how modeled macroeconomic variables impact public and private strands of US investment growth in a comparative analysis. Methodology employed in this inquest is modeled on the assumption that public and private investment growth might not respond in a similar manner to specific external macroeconomic condition or stimulus. For instance, this study anticipates significant disparity in how private and public investment growth responds to unique macroeconomic condition such as inflation expectations. If disparity in how these investment components responds to macroeconomic condition is detected, the phenomenon will provide strong evidence to the effect that one-sided investment policy drive, might not be enough to promote significant growth in overall investment; since the two investment components might require different policy approaches. This study further projects that conditions such as macroeconomic uncertainty, inflation expectations etc. may not impact private and public (federal government and states) investment growth proportionally. Again, if it is found for instance, that private investment growth respond more to macroeconomic uncertainty than public investment growth; then, the condition could be an indication that in periods of significant macroeconomic uncertainty federal and state governments tend to be more active in their investment drive; often in an attempt to shore-up the economy; whereas private investors rationally restrict investment growth.

\section{Structure of US Private and Public Investment Growth}

Historical trend analysis of US private and public net domestic investment growth show that, over the past five decades (1960 to 2013), quarterly growth conditions associated with the two investment strands have varied significantly. Graphical plot of the historical data associated with the two investment strands for instance, indicate that public investment growth dynamics over the period under review have been significantly more volatile compared to net domestic investment growth in the private sector. Figures 1 and 2 , illustrates quarterly investment growth dynamics associated with US public and private sector investment growth. Figure 1 charts historical private investment growth trend between 1960 and 2012. From this trend depiction, it is evident that historically, private investment growth trend has been fairly stable with the exception of periods during and after the 2008 recession. Conditions during and after the 2008 economic decline is showed to have perturbed a relatively sturdy historical quarterly trend; reaction to this economic shock is captured by significant volatility around the period in question in Figure 1. The same trend conditions however, cannot be said about quarterly growth behavior characterizing public investment growth captured in figure 2 . 


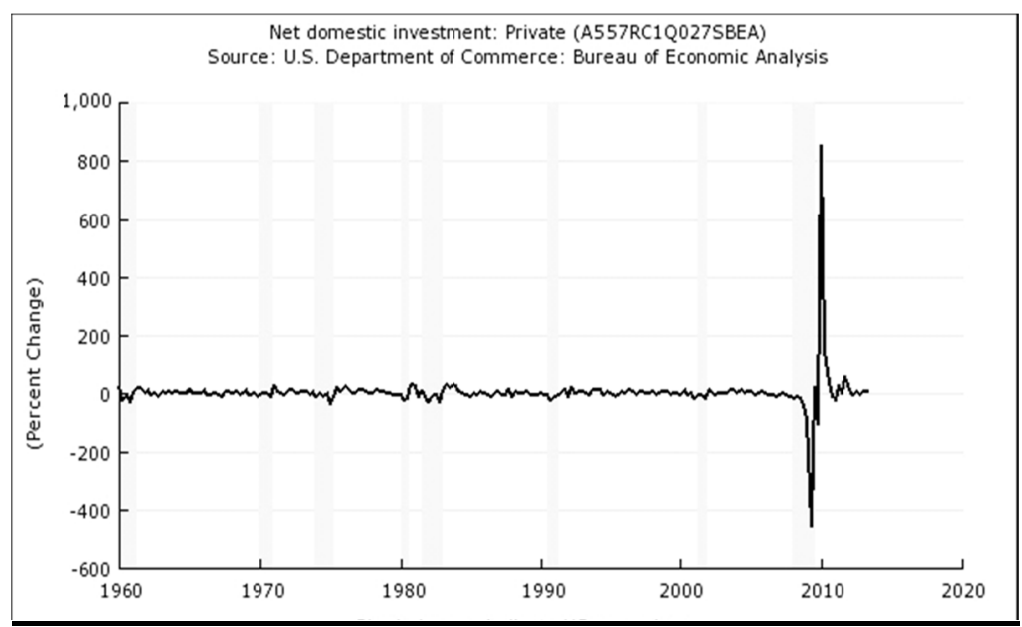

Figure 1. US quarterly private investment growth (percentage change: 1960-2012)

Investment growth trend captured in Figure 2 suggest that public investment growth conditions over the period under consideration, exhibits two major volatile episodes. The first episode occurred in the early part of the 1970s; and the second episode which persisted for significant period of time, lasted from the early part of the 1990s to the early part of the year 2000. These trend features are significantly different from trend conditions captured in figure 1 which suggests US private investment growth conditions tend to be fairly stable compared to public investment growth. Figure 2 further suggest that compared to private investment growth, public investment growth does not experience much volatility during periods of significant economic perturbation. Comparative analysis of growth trends associated with the two investment strands during the recent recessionary period further show that private investment growth trend experienced significant fluctuations during the recessionary period (2008-2011) than public investment growth which showed a fairly stable trend condition.

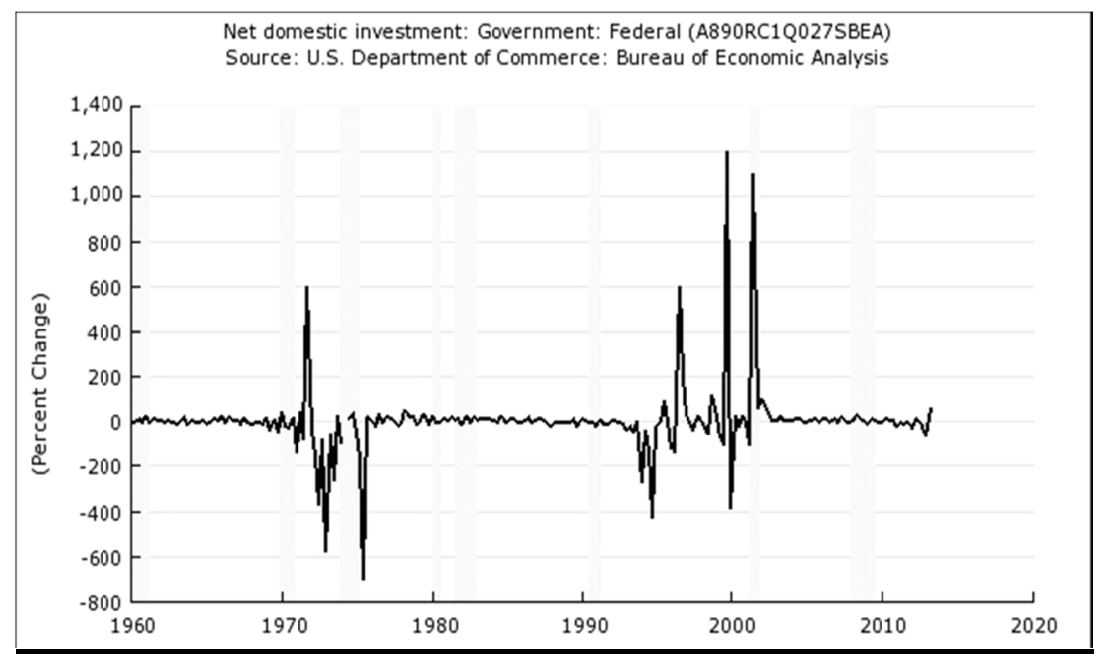

Figure 2. US quarterly public investment growth (percentage change: 1960-2012)

\section{Macroeconomic Conditions and US Private Investment Growth}

\subsection{Macroeconomic Uncertainty and Private Investment Growth}

In this study, the extent to which vague macroeconomic conditions influence private investment growth is assumed to depend on the behavior of private investors operating in such business environment. We hypothesize that effects of macroeconomic uncertainty on private investment growth will tend to be more pronounced in business environment dominated by rational investors, than one dominated by investors 
whose decisions are less informed by prevailing and projected market conditions. Following this line of reasoning, we posit that all things being equal, private investment growth could be constrained significantly in macroeconomic environment characterized by persistent uncertainty and dominated rational investors. This position stems from the view that in such macroeconomic environment, profitability signals on investments tend to be distorted or are less informative leading to conservative behavior on the part of the average rational investor. Existing literature for instance suggest that, in periods of macroeconomic uncertainty, rational investors often seek to trade off returns from early commitment to invest, with the benefits of increased information which could be gained by delaying proposed investment projects. This behavior is based on the believed that additional information gained during such waiting period could be crucial in making optimal investment decisions. Bernanke B. (1983) for instance, showed that uncertainty generate investment cycles which increases the incentive to hold-off on projects with the hope of gaining additional information before any investment commitment.

Apart from rational behavior analysis which explains how macroeconomic uncertainty influence private investment growth, a review of existing literature further provide evidence in support of the view that macroeconomic uncertainty could be inimical to private investment growth. For instance, in a study focusing on how macroeconomic uncertainty influence private investment growth among developed economies, Federer (1993) showed that macroeconomic uncertainty has negative impact on US equipment investment growth. Again, a submission by Serven (1998) further found existence of systematic and robust negative relationship between uncertainty and private investment growth. Additionally, in an empirical analysis based on an error correction framework, Ahmad, Imtiaz and Qayyum, Abdul, (2008) and (2009) respectively, also showed that Macroeconomic uncertainty has negative impact on private investments. These studies in part, show that significant empirical evidence exist in support of the view that macroeconomic uncertainty correlates negatively with private investment growth. However, as alluded to in an earlier submission, this study is geared towards verifying whether such macroeconomic condition has similar constraining impact on public investment growth in a comparative analysis. Macroeconomic uncertainty variable in this study is modeled as a generalized arch function; GARCH $(1,1)$ based on US GDP growth; and is meant to capture volatility associated with US economic performance. The following GARCH function is used in estimating macroeconomic uncertainty variable tested in this study.

$$
h_{t}=\omega+\alpha_{1} \varepsilon_{t-1}^{2}+\beta_{1} h_{t-1}
$$

where, $\alpha_{1}$ and $\beta_{1}$, are all nonnegative; and $\omega>0$.

\subsection{Inflation Expectations and Private Investment Growth}

The notion that decisions made by private firms and individual investors are influenced by relevant market information, including reasonable expectations, is consistent with predictions of rational expectation theory and bounded rationality concept propounded by John Muth, (1961) and Sargent, Thomas J. (1993). Although the debate on how such expectations are formed and how they ultimately impact market decisions is still ongoing, the view that such expectations impacts decisions made by economic actors (such as investors) to some degree, is supported in existing related macroeconomic literature. Most macroeconomic models for instance, are built with implied assumption that economic agents (investors, consumers etc.) maximize utility based on well-defined scale of preference which reflects available information and reasonable expectations. Economic agents such as investors are for instance, deemed to utilize all relevant information including inflation expectations in making crucial business decisions with significant impact on success or failure. These agents will for instance incorporate into their decision making process the potential for inflation; since realization of such condition could impact purchasing power; assets value; and expected gains. Inflation expectations in this instance have been shown to have self-fulfilling property in macroeconomic models; in that, such expectations are often immediately compensated for in ongoing business decisions in the real economy. This self-fulfilling condition, thus, suggests significant correlation between expected inflation, realized inflation and investment growth dynamics.

Bernanke B. (2004) for instance, argued that an essential prerequisite for controlling inflation is controlling inflation expectations; because realized inflation tends to mimic prior inflation expectation trajectory. Giving these background, we project that inflation expectations could stifle private investment growth all things being equal. This projection stems from the belief that inflation expectations might discourage savings; a key driver of investment growth. Additionally, such inflation expectation could also constrains investment growth because businesses in such environment might find it difficult to predict demand 
conditions due to expectations of significant increase in general price levels. Inflation expectations variable employed in this study is adopted from the Federal Reserve Economic Data (FRED) published by the St. Louis Federal Reserve.

\subsection{Fiscal Policy Volatility and Private Investment Growth}

According to Chibber and Dailami (1990), and Ndikumana (2005), there are varied channels through which fiscal policy can impact private investment growth. Conclusions from these studies suggest that fiscal policy can influence investment growth through three key channels: (1) impact on volume of savings available for investments via taxes; (2) through investor confidence based on the nature of expected policies; and (3) through tighter fiscal policies which reduces expenditure on investments among corporations. In-depth analysis further indicates fiscal policy volatility defines how these named channels ultimately influence private investment growth. Apart from these conclusions, significant empirical work also exist suggesting significant relationship between variability in prevailing macroeconomic policies (fiscal policy) and investment growth. For instance, in a study focusing on how policy volatility impact private investment decisions among emerging economies, Chen and Funke (2003) submitted that rational investors tend to withhold investments until they are convinced about the effects of existing or expected policies. This conclusion suggests that if investors expect fiscal policies to be favorable to investments, such expectations will have positive impact on current and future investment decisions and vice versa. Additionally, Le Quan (2004) also concludes that policy volatility has significant impact on private investment. Le's study further provided evidence to the effect that variability in government political capacity to enforce policies deemed necessary by investors, could hinder private investment growth. This study consequently, project that all things being equal, fiscal policy volatility, through its effect on the rate of savings, consumer and investor confidence could have dampening effect on investment growth. Fiscal policy volatility variable in this study is estimated using GARCH process similar to one used in modeling macroeconomic uncertainty variable. Garch $(1,1)$ process in this case captures trend volatility in government revenue, as a means of tracking fiscal policy dynamics.

\subsection{Recession Expectations and Private Investment Growth}

Recession expectations variable featured in this study captures anticipated macroeconomic environment characterized by significant decline in economic activity among various sectors of an economy. In such environment, rational behavior concept alluded to earlier, again projects significant negative impact on investments growth due to expectations of adverse macroeconomic conditions. In other words, if economic actors (investors) anticipates significant decline in economic activities (Note 2) or if prevailing economic indicators suggest impending recessionary conditions, such condition, is projected to have negative impact on private investment growth because of heightened potential for lower profit margins. A study of existing literature suggests investments growth trajectory tends to revolve around prevailing macroeconomic conditions, as well as investors' ability to make accurate forecast pertaining to future market and macroeconomic conditions. Consequently, a forecast of impending decline in economic activity-i.e., recession expectation; is expected to have negative impact on investment decisions and ultimately, investment growth. For instance, if a forecast of macroeconomic condition such recessionary expectations are found to be credible (a threat to investment viability), investment growth will be negatively impacted because the threat will compel rational investors to hold off on planned projects. From these discussions, it is evident that significant portion of the variability in private investment growth tend to reflects macroeconomic expectations-i.e., forecasted or projected macroeconomic conditions. If private investors envisage significant positive trend in economic activity, such expectation will drive substantial growth in investment in the real economy and vice versa. Positive economic expectations, such as projected sustained growth in consumption expenditures will for instance occasion positive responds among investors bringing about significant growth in investment; however, a forecast of potential decline in consumer confidence could ultimately constrain investment growth. Given these analyses, this study projects that recession expectations-a negative macroeconomic condition, will engender negative responds among private investors; ultimately leading to anemic investment growth. It is further projected that recession expectation will tend to have more constraining effects on private investment growth than public investment growth. These projections are verified in subsequent empirical analysis. Recession expectations variable employed in this study is adopted from the Federal Reserve Economic Data (FRED)—St. Louis Federal Reserve.

\section{Macroeconomic Conditions and Public Investment Growth}

Reviewed literature identifies legion of factors and conditions as being responsible for fluctuations in public 
investment growth. Although these factors ranges from macroeconomic to geo-political conditions, most of the reviewed studies still points to prevailing macroeconomic condition or performance as a key factor driving public investment growth. For instance, in their assessments of evolution of determinants of public investment in Europe, Välilä T. and Mehrotra A. (2005) found that public investment growth among economies in the European Monetary Union has been determined predominantly by national income (GDP growth), budgetary conditions/policies, and fiscal sustainability considerations. This conclusion suggests that among European economies, prevailing macroeconomic conditions, i.e., national income performance (GDP growth) as well as factors impacting budgetary conditions (fiscal policy considerations) drives public investment growth dynamics. Additionally, in an earlier study focusing on determinants of public investment growth, Galí and Perotti (2003) also concluded that public investment behavior tend to reflect prevailing macroeconomic conditions; and that, a percentage point change in expected output gap, moves up public investment growth by 0.04 percentage points. This conclusion further point to macroeconomic conditions as being a key determinant or factor explaining variability in public investment growth. Turrini (2004), whose study also focused on determinants of public investment growth in the EU, further concludes that public investment (as percentage of GDP) tends to decline with GDP growth and increasing public debt. This condition which further suggests inverse trend relationship between economic performance and public investment growth; thus, establishing another public investment growth-macroeconomic condition link. Apart from these macroeconomic considerations which dominate the literature, there is also significant evidence suggesting that portions of public investments made, tend to be acyclical in nature; that is; such investments tend to occur independent of the overall state of the economy or prevailing macroeconomic conditions. Such investments have been shown to be politically driven or motivated.

If public investment growth is predominantly driven by macroeconomic and at times, acyclical conditions as noted above, then it is likely that macroeconomic conditions modeled in this study could impact its growth trajectory or have absolutely no impact on it. This conclusion stems from the view that, if public investment decisions could be acyclical, then, it's possible for significant amount of public investment to occur regardless of prevailing or projected macroeconomic conditions. In order words, significant growth in public investments could still occur even during periods of significant macroeconomic uncertainty, inflation or recession expectations. Macroeconomic conditions tested in this study projects some form of uncertainty in an economy; however, this notwithstanding, one cannot conclude that such uncertainty or expectations will constrain public investment growth without robust holistic empirical analysis due to potential for acyclical investment decisions. Consequently, no such projections about the association between public investment growth and modeled macroeconomic conditions are attempted in this section; we rather allow empirical results verifying the nature of the relationship between the variables to inform final conclusions.

\section{Private and Public Investment Growth and Macroeconomic Conditions}

\subsection{Model Specification}

Controlling for effects of traditionally verified determinants of private and public investment growth such as interest rate, GDP growth etc., relationships between private investment growth; public investment growth; and modeled macroeconomic conditions are tested in a linear framework as follows:

$$
\begin{gathered}
\text { Priv-Inv }_{t}=\alpha_{j}+\beta \text { Munc }+\beta \text { InfExp }+\beta \text { FiscVol }+\beta \text { RecEx }+\varepsilon_{t} \\
\text { Publ-Inv }_{t}=\alpha_{j}+\beta \text { Munc }+\beta \text { InfExp }+\beta \text { FiscVol }+\beta \text { RecEx }+\varepsilon_{t}
\end{gathered}
$$

Where

Priv-Inv ${ }_{\mathrm{t}}$ and Publ-Inv $\mathrm{t}_{\mathrm{t}}=$ Private and Public Investment Growth respectively;

Munc $_{\mathrm{t}}=$ Macroeconomic uncertainty parameter derived through garch process;

InfExp $\mathrm{p}_{\mathrm{t}}=$ Inflation expectations capturing projected increase in general price levels;

$\mathrm{FiscVl}_{\mathrm{t}}=$ Fiscal Policy volatility;

$\operatorname{RecEx}_{\mathrm{t}}=$ Recession Expectations, perceived imminent slowdown in economic activities;

$\varepsilon_{\mathrm{t}}=$ Random error term assumed independent and identically distributed (iid).

Using equations (2) and (3), dynamic private and public investment growth models are estimated via error correction process. This empirical process estimates short and long run relationships between US private 
investment growth; public investment growth; and stated macroeconomic conditions. This estimation process is achieved using autoregressive distributed lag model (ARDL). ARDL test framework is adopted in this empirical process because it has been shown to yield significant results irrespective of the order of integration of variables in treatment; that is, whether study regressors are purely $\mathrm{I}(0), \mathrm{I}(1)$, or mutually cointegrated; Pesaran et al. (2001). Further evidence provided by Alam and Quazi, (2003), indicates the ARDL approach yield robust estimates even when explanatory variables are endogenous. Additionally, instead of ARDL bound test approach which relies on critical bound values suggested by Pesaran et al. (2001), this study opt for bounds test critical values suggested by Narayan (2004). Critical bound values suggested by Narayan have been shown to be more accurate for small sample data sets $(<500)$ compared to those propounded by Pasaran et al. (2001) which dominates studies in the finance and economics literature. Following Ahmed Imtiaz and Qayyum Abdul (2007), long run effects of modeled macroeconomic conditions on US private and public investment growth using ARDL technique are modeled from equations (2) and (3) as follows:

$$
Y_{t}=\mu+\Pi_{1} Y_{t-1}+\Pi_{2} Y_{t-2}+\ldots \ldots \ldots .+\Pi_{k} Y_{t-k}+e_{t}
$$

Where $Y_{t}$ is a vector of dependent and independent variables in the model (Private and Public investment growth, macroeconomic uncertainty, recession expectations, inflation expectations and fiscal policy volatility), $\mu$, a vector of constant term, and $e_{t}$, the error or disturbance term assumed to be (iid) with $\left(0, \sigma^{2}\right)$. Using the difference notation, $\Delta=1-\mathrm{L}$, where $\mathrm{L}$ is the lag operator; a dynamic error correction model (ECM) of how public and private investment growth responds to modeled macroeconomic conditions can further be derived from as follows:

$$
\Delta Y_{t}=\mu+\sum_{i=1}^{p-1} \Gamma_{i} \Delta Y_{t-i}+\Pi Y_{t-k}+E c m_{t-1}+e_{t-k}
$$

Where: $\Gamma_{\mathrm{i}}=-\left(\mathrm{I}-\Pi_{1}-\ldots-\Pi \mathrm{i}\right), \mathrm{Ecm}=$ error correction parameter and $\mathrm{i}=1,2,3, \ldots \mathrm{k}-1$.

Error correction model in equation (5) estimates how private and public investment growth responds to stated macroeconomic conditions in the short run.

In the following pre-estimation analysis, stationary conditions characterizing variables employed in the study are verified; afterwards, this section proceeds to examine long and short run effects of stated macroeconomic conditions on public and private investment growth in a comparative analysis.

\subsection{Empirical Estimates, Results and Discussions}

\subsubsection{Data and Variables}

Comparative empirical analysis conducted in this study utilizes data from St. Louis Fed and Bureau of Economic Analysis. The data is made up of quarterly time series spanning the period 1960 to 2012 . Variables employed include, inflation expectations ( $\left.\operatorname{InfExp}_{\mathrm{t}}\right)$, recession expectations $\left(\operatorname{RecEx}_{\mathrm{t}}\right)$, Macroeconomic Uncertainty $\left(\right.$ Munc $\left._{t}\right)$ and fiscal policy volatility $\left(\mathrm{FiscVol}_{\mathrm{t}}\right)$ and Private and Public investment growth (Priv-Inv $v_{t}$ and Pub-Inv $v_{t}$ ) respectively. With the exception of recession expectations and inflation expectations, variables in treatment are all made up of percentage change in the absolute macroeconomic indicator from quarter to quarter.

\section{Assessing Unit Root Conditions}

\begin{tabular}{|c|c|c|c|c|c|c|}
\hline \multirow{3}{*}{ Variables } & \multirow{3}{*}{$\begin{array}{c}\text { ADF Test } \\
\text { Optimal } \\
\text { Lag Order }\end{array}$} & \multicolumn{5}{|c|}{ Philips Perron Test } \\
\hline & & Test & D $\quad 1$ & Newey-West & $\mathrm{D}-\mathrm{l}$ & $\mathrm{Z}(\mathrm{t})$ tau \\
\hline & & Statistics & Results & lag & Kesuits & Statistics \\
\hline Publ-Inv $t_{t}$ & 5 & $-14.53 * * *$ & $\mathrm{I}(0)$ & 4 & $\mathrm{I}(0)$ & $-14.72 * * *$ \\
\hline $\operatorname{Priv}_{-I_{\mathrm{t}}}$ & 5 & $-15.26 * * *$ & $\mathrm{I}(0)$ & 4 & $\mathrm{I}(0)$ & $-15.36^{* * *}$ \\
\hline Munc $_{t}$ & 5 & $-4.92 * * *$ & $\mathrm{I}(0)$ & 4 & $\mathrm{I}(0)$ & $-5.064 * * *$ \\
\hline $\operatorname{InfExp}_{t}$ & 5 & -2.05 & $\mathrm{I}(1)$ & 4 & $\mathrm{I}(1)$ & -2.38 \\
\hline FiscVol $_{t}$ & 5 & $-10.10^{* * *}$ & $\mathrm{I}(0)$ & 4 & $\mathrm{I}(0)$ & $-10.05 * * *$ \\
\hline $\operatorname{RecEx}_{t}$ & 5 & $-12.32 * * *$ & $\mathrm{I}(0)$ & 4 & $\mathrm{I}(0)$ & $-12.12 * * *$ \\
\hline
\end{tabular}

Table 1. Unit root test analysis

Indication of stationary condition: $* * *$ 


\subsubsection{Univariate Time Series Analysis (Unit Root Test)}

Stationary conditions associated with variables employed in this study are verified using optimum lag order selected by Akaike Information Criterion (AIC). AIC test estimate suggests optimum lag order of 5 for the following unit root tests. Table 1 report unit root test for stationary conditions characterizing study variables using both the Augmented Dickey-Fuller test (ADF)-Dickey-Fuller (1981)) and the Phillip-Perron (1988) (PP) unit root tests procedures. Results reported in table 1 indicate employed variables are stationary with the exception of inflation expectations in both testing procedures.

\subsubsection{Multivariate Cointegration Analysis}

Multivariate cointegration analysis in this section precedes tests for short and long run dynamic relationships between modeled macroeconomic conditions and US Private and Public investment growth. This cointegration procedure test the hypothesis of no cointegration between Private investment growth; Public investment growth; and modeled macroeconomic conditions as specified earlier. These analyses are meant to verify existence of long run relationships between key dependent variables in this study, and modeled macroeconomic conditions. Estimation method adopted relies on ARDL-bound test approach to cointegration testing using F-test manipulation technique to make judgment on cointegrating conditions between variables in treatment. This cointegration technique utilizes critical bound values to determine relative cointegrating relationships between variables of interest. As indicated earlier, this study adopts critical bound values propounded by Narayan (2004). Using this technique, if computed or estimated F-test statistic is found to exceed adopted upper critical bound value, the null hypothesis of no cointegration between variables in treatment can be rejected; however, if computed F-test statistic falls below adopted lower bound value, the null hypothesis of no cointegrating relationship between tested variables cannot be rejected. If computed test statistic however, falls between the upper and the lower bound values, then no conclusive admission could be made about the relationship between variables in treatment. The following procedure test the hypothesis of an existence of $\mathrm{k}$ cointegration vector(s) against condition of no-existence of such vector(s) z. That is, existence of long run relationship between private investment growth, public investment growth and stated macroeconomic conditions. The following null hypothesis is thus tested:

$$
H_{o(k)}: \operatorname{rank}(\Pi)=k
$$

Against the alternative hypothesis

$$
H_{l(k)}: \operatorname{rank}(\Pi)=z
$$

Tables 2 and 3 report test results verifying long run or cointegrating relationships between the two stated investment growth strands and key explanatory variables using the F-test technique. Test statistic values reported in both tables 2 and 3, that is (32.35 and 30.13 respectively) far exceeds upper critical bound values at $1 \%, 5 \%$ and $10 \%$ significance levels; consequently, the null hypothesis of no cointegration or long run relationship between US private and public investment growth and modeled explanatory variables can be rejected in support of significant long run relationship.

\begin{tabular}{|c|c|c|c|c|}
\hline Test Statistics & Value & Alpha Level & $\begin{array}{l}\text { Lower Bound } \\
\text { Critical Value }\end{array}$ & $\begin{array}{l}\text { Upper Bound } \\
\text { Critical Value }\end{array}$ \\
\hline \multirow[t]{4}{*}{ F-Statistic } & 32.35 & & $\mathbf{I}(\mathbf{0})$ & $\mathbf{I}(\mathbf{1})$ \\
\hline & & $1 \%$ & 3.42 & 4.88 \\
\hline & & $5 \%$ & 2.55 & 3.71 \\
\hline & & $10 \%$ & 2.17 & 3.22 \\
\hline
\end{tabular}

Table 2. Bound test for cointegration (private investment growth)

Critical values based on Bound Critical Values Propounded by Narayan (2004), Case II. $\left(\mathrm{R}^{2}=0.59\right)$. 
Table 3. Bound test for cointegration (Public Investment Growth)

\begin{tabular}{|c|c|c|c|c|}
\hline \multirow{2}{*}{ Test Statistics } & \multirow{2}{*}{ Value } & \multirow{2}{*}{ Alpha Level } & Lower Bound & Upper Bound \\
\hline & & & Critical Value & Critical Value \\
\hline \multirow[t]{4}{*}{ F-Statistic } & 30.13 & & $\mathbf{I}(\mathbf{0})$ & I(1) \\
\hline & & $1 \%$ & 3.42 & 4.88 \\
\hline & & $5 \%$ & 2.55 & 3.71 \\
\hline & & $10 \%$ & 2.17 & 3.22 \\
\hline
\end{tabular}

Critical values based on Bound Critical Values Propounded by Narayan (2004), Case II. ( $\mathrm{R}^{2}=0.58$ ).

\section{Empirical Results: Short and Long Run Relationships and Comparative Analysis}

\subsection{Short Run and Long Run Dynamics of Private and Public Investment Growth}

This section estimate and compare relative disparities in how modeled macroeconomic conditions already stated, impact US public and private investment growth. This analysis is accomplished through short and long run elasticity procedures through ARDL-Error Correction framework. The first step in this process involves estimating parsimonious private and public investment growth error correction model based on equation (5) after pre-estimation econometric conditions have been met. The second testing procedure based on equation (4), on the other hand, verifies how stated macroeconomic conditions influence public and private investment growth in the long run. With significant cointegration or long run relationship between US private and public investment growth; and modeled explanatory variables already established, an error correction model estimating how stated investment strands responds to modeled macroeconomic conditions in the short run is tested. Tables 4 and 5 present coefficient estimates of how modeled macroeconomic conditions influence private and public investment growth in the short run.

\subsection{Short-Run Public Investment Growth and Macroeconomic Conditions}

Coefficient estimates reported in table 4 shows that with the exception of recession expectations or projected significant decline in economic activities, all modeled macroeconomic conditions tested are insignificant in explaining variability in public investment growth in the short run. These results suggest that, among the macroeconomic conditions tested, only recession expectations or impending decline in economic activity has some influence public investment growth. Recession expectations coefficient reported in table 4 however, suggest the condition rather tend to have positive impact on public investment growth; an outcome which is consistent to some extent with observed public investment behavior by federal and state governments. This result, thus, intimates that public investments (by the federal and local governments) are often made to either prevent substantial decline in economic activities or shore-up stagnating economic trend during periods of constrained economic performance. It further suggests that federal and state investment expenditures responds positively to projected or expected decline in economic activities all things being equal.

Table 4. Error correction — short run results (Public Investment Growth)

\begin{tabular}{|c|c|c|}
\hline Variables & $\begin{array}{c}\text { Public Investment } \\
\text { Growth }\end{array}$ & $\begin{array}{c}\text { Standard } \\
\text { Error }\end{array}$ \\
\hline ld. Munc ${ }_{t}$ & -0.1395 & 0.3564 \\
\hline ld. $\operatorname{InfExp}_{\mathrm{t}}$ & 0.0522 & 0.8191 \\
\hline 1d. $\mathrm{FiscVol}_{\mathrm{t}}$ & 0.0199 & 0.0171 \\
\hline 1d. $\operatorname{Rec} \mathrm{x}_{\mathrm{t}}$ & $0.0515^{*}$ & 0.0228 \\
\hline $\mathrm{ECT}_{\mathrm{t}-1}$ & $-0.9955 * * *$ & 0.0768 \\
\hline Const & 0.1429 & 0.6152 \\
\hline
\end{tabular}




\subsection{Short-Run Private Investment Growth and Macroeconomic Conditions}

Empirical results reported in table 5 vary significantly from those presented in table 4 . Reported coefficient estimates in this instance, suggests macroeconomic uncertainty and fiscal policy volatility have significant negative impact on US private investment growth in the short run. The results also show that in the short run, inflation and recession expectations have no statistically significant impact on private investment growth all things being equal; possibly due to lag period in how investors respond to such macroeconomic conditions. Among macroeconomic conditions tested, this study also finds that private investment growth respond more negatively to macroeconomic uncertainty than other variables found to be significant in explaining variability in private investment growth in the short run (i.e. fiscal policy volatility).

Table 5. Error correction—-short run results (Private Investment Growth)

\begin{tabular}{lcc}
\hline Variables & Private Investment Growth & Standard Error \\
\hline ld. $_{\text {Munc }}$ & $-7.2866^{* * *}$ & 2.0497 \\
ld. $\mathrm{InfExp}_{\mathrm{t}}$ & -0.1499 & 2.9987 \\
ld. FiscVol & $-0.1438^{*}$ & 0.0635 \\
$\mathrm{ld}_{\mathrm{fecEx}} \mathrm{R}$ & -0.1273 & 0.0850 \\
$\mathrm{ECT}_{\mathrm{t}-1}$ & $-0.5208^{*}$ & 0.2831 \\
$\mathrm{Const}$ & -0.2375 & 1.6702 \\
\hline $\mathrm{R}^{2}=0.51$ & &
\end{tabular}

\subsection{Short Run Comparative Analysis}

Coefficient estimates of the relationship between stated dependent variables and modeled macroeconomic conditions reported in tables 4 and 5 have shown that US private and public investment growth respond to, or are impacted by varied macroeconomic conditions in the short run. The results also show that adverse macroeconomic conditions do not necessarily impact all investments strands (private and public) negatively in the short run as is ordinarily believed. This study for instance found that, public investment growth tends to trend positively with recession expectations; that is, anticipation of significant decline in economic activities in the short run. In other words, recession expectations rather enhance public investment growth. Additionally, the results further demonstrate that the two investment strands tested, may not always trend in the same direction in responds to a specific macroeconomic condition.

\subsection{Long-Run Private and Public Investment Growth Dynamics-A comparative Analysis}

Results presented in table 6 illustrate effects of modeled macroeconomic conditions on US private and public investment growth in the long run. Reported coefficient estimates suggest that unlike conflicting short run relationships analyzed above, private and public investment growth components tested in this section tend to respond to similar adverse macroeconomic conditions. This study finds that among macroeconomic conditions tested; only macroeconomic uncertainty and recession expectations are significant in explaining variability in both US private and public investment growth in the long run. Reported estimates also show that whereas the two macroeconomic conditions tend to constrain private investment growth in the long run, recession expectation or anticipation of significant decline in economic activity rather augment or have positive impact on public investment growth in the long run; a condition which confirms similar outcome reported in earlier short run analysis. Comparatively, our results further suggest that effects of macroeconomic uncertainty and recession expectations on private investment growth tend to be more severe than effects on public investment growth. For instance, in table 6, a percentage growth in intensity in the two macroeconomic conditions in question, is found to have more significant impact on private investment growth than public investment growth. Coefficient estimates for private investment growth in this regard are significantly higher in absolute terms compared to those of public investment growth during periods of macroeconomic uncertainty and recession expectations. This comparative analysis further reinforce the view that private investment growth conditions are relatively more vulnerable to adverse macroeconomic conditions than public investment growth. It also supports the view that private investments react more significantly to prevailing macroeconomic conditions than public investments. 
Table 6. Effects of macroeconomic conditions on US private and public investment growth

(1)

(2)

\begin{tabular}{lccccc} 
Variables & Public Investment Growth & Standard Errors & Variables & Private Investment Growth & Standard Errors \\
\hline $1 . \mathrm{Munc}_{\mathrm{t}}$ & $-0.6779^{*}$ & 0.3652 & $1 . \mathrm{Munc}_{\mathrm{t}}$ & $-3.8922^{* *}$ & 1.2728 \\
$1 . \mathrm{InfExp}_{\mathrm{t}}$ & -0.0719 & 0.2034 & $1 . \mathrm{InfExp}_{\mathrm{t}}$ & -0.1104 & 0.7150 \\
$1 . \mathrm{FiscVol}_{\mathrm{t}}$ & 0.0271 & 0.0200 & $1 . \mathrm{FiscVol}_{\mathrm{t}}$ & 0.0936 & 0.0698 \\
$1 . \mathrm{RecEx}_{\mathrm{t}}$ & $0.0530^{*}$ & 0.0291 & $1 . \mathrm{RecEx}_{\mathrm{t}}$ & $-0.2775^{* *}$ & 0.1050 \\
Const & .0153 & 0.7521 & Const & 4.9322 & 2.6476 \\
\hline
\end{tabular}

$* \mathrm{p}<0.05,{ }^{* *} \mathrm{p}<0.01, * * * \mathrm{p}<0.001$ Levels of significance.

\subsection{Conclusions and Recommendations}

This study verified how private and public investment growth trends in US respond to specific macroeconomic conditions in a comparative analysis. Our results show that modeled macroeconomic conditions have much lower significant impact on public investment growth in the short run than private investment growth. This study also finds that macroeconomic uncertainty and recession expectations have significant impact on both public and private investment growth in the long run; and that the two macroeconomic conditions tend to constrain private investment growth more than public investment growth. Comparative analysis following the various estimates further indicate that contrary to some projections, recession expectations tend to rather have positive impact on public investment growth; but constrains or have significant negative impact on private investment growth. Estimated coefficients further suggest that private investment growth dynamics are more susceptible to adverse macroeconomic conditions than public investment growth. These reported differences in vulnerability to macroeconomic conditions between the two investment strands suggest that policies geared towards promoting sustained investment growth, and consequently economic growth, should address such unique features. Reported results further highlight the need for formulated policies to critically address private investment growth's vulnerability to prevailing or anticipated macroeconomic conditions such as those modeled in this study. It further calls for concerted efforts in formulating adaptive policies to deal with ever-evolving macroeconomic conditions since 'one-size fit all' type of investment oriented policies might not be effective in promoting holistic investment growth.

\section{References}

Abaidoo, R., \& Ofosuhene, K. D. (2013). Corporate Profit Growth, Macroeconomic Expectations and Fiscal Policy Volatility. International Journal of Economics and Finance, 5(8). http://dx.doi.org/10.5539/ijef.v5n8p25

Ahmad, I., \& Qayyum, A. (2009). Role of Public Expenditures and Macroeconomic Uncertainty in Determining Private Investment in Large Scale Manufacturing Sector of Pakistan. International Research Journal of Finance and Economics, 26.

Ahmad, I., \& Qayyum, A. (2008). Effect of Government Spending and Macro-Economic Uncertainty on Private Investment in Services Sector: Evidence from Pakistan European Journal of Economics. Finance And Administrative Sciences, 11.

Ahmed, I., \& Qayyum, A. (2007). Do Public Expenditure and Macroeconomic Uncertainty matter to Private Investment Growth? Evidence from Pakistan. The Pakistan Development Review, 46(2), 145-161.

Aizenman, J., \& Marion, N. (1999). Volatility and Investment: Interpreting Evidence from Developing Countries. Economica, 66, 157-179. http://dx.doi.org/10.1111/1468-0335.00163

Alam, M. I., \& Quazi, R. M. (2003). Determinant of capital flight: An econometric case study of Bangladesh. International Review of Applied Economics, 17, 85-103. http://dx.doi.org/10.1080/713673164

Armantier, O., Wändi, B. de B., Giorgio, T., Wilbert, Van Der K1., \& Basit, Z. (2011). Inflation Expectations and Behavior: Do Survey Respondents Act on their Beliefs? Federal Reserve Bank of New York Staff Reports, no. 509, August 2011.

Asante, Y. (2000). Determinants of Private Investment Behavior.

Bernanke, B. S. (1983). Irreversibility, Uncertainty, and Cyclical Investment. Quarterly Journal of Economics, 
85-106. http://dx.doi.org/10.2307/1885568

Bernanke, B. (2004). The Economic Outlook and Monetary Policy. Speech at the Bond Market Association Annual Meeting, New York.

Bloom, N., Bond, S., \& Reenen, J. V. (2007). Uncertainty and Investment Dynamics. Review of Economic Studies, 74, 391-415. http://dx.doi.org/10.1111/j.1467-937X.2007.00426.x

Chen, Y. F., \& Michael, F. (2003). Option Value, Policy Uncertainty, and the Foreign Direct Investment Decision. HWWA Discussion Paper No. 234.

Chhibber, A., \& Dailami, M. (1990). Fiscal Policy and Private Investment in Developing Countries: Some Recent Evidence on Key Selected Issues. The World Bank, Policy, Research and External Affairs, Working Papers in Development Economics, WPS 559.

Chirinko, R. S. (1993). Business Fixed Investment Spending: Modeling Strategies, Empirical Results, and Policy Implications. Journal of Economic Literature, 31, 1875-1911.

Dickey, D., \& Fuller, W. (1981). Likelihood ratio statistics for autoregressive time series with a unit root. Econometrica, 49, 1057-1072. http://dx.doi.org/10.2307/1912517

Escaleras, M., \& Thomakos, D. (2008). Exchange rate uncertainty, sociopolitical instability and private investment: empirical evidence from Latin America. Review of Development Economics, 12(2), 372385. http://dx.doi.org/10.1111/j.1467-9361.2007.00378.x

Federer, J. (1993). The Impact of Uncertainty on Aggregate Investment Spending. Journal of Money, Credit and Banking, 25, 30-48. http://dx.doi.org/10.2307/2077818

Galí, J., \& Perotti, R. (2003). Fiscal policy and monetary integration in Europe. Economic Policy, October, 533-572. http://dx.doi.org/10.1111/1468-0327.00115_1

Hausmann, R., \& Michael, G. (1995). Macroeconomic Volatility in Latin America: Causes, Consequences, and Policies to Assure Stability. Unpublished manuscript, Inter-American Development Bank, Washington, D.C.

John, M. (1961). Rational Expectations and the Theory of Price Movements. Econo-metrica, 29(July), 315335. http://dx.doi.org/10.2307/1909635

Jorgenson, D. (1963). Capital Theory and Investment Behavior. American Economic Review, 53, $247-259$.

Le Quan, V. (2004). Political and Economic Determinants of Private Investment Growth. Journal of International Development J. Int. Dev, 16, 589-604. http://dx.doi.org/10.1002/jid.1109

Moguillansky, G. (2002). Investment and Financial Volatility in Latin America. CEPAL Review, 77, 45-63.

Narayan, P. K. (2004). Reformulating critical values for the bounds F-statistics approach to cointegration: An application to the tourism demand model for Fiji. Department of Economics Discussion Papers, No. 02/04, Monash University, Melbourne.

Ndikumana, L. (2005). Can Macroeconomic Policy Stimulate Private Investment in South Africa? New Insights from Aggregate and Manufacturing Sector-level Evidence. Working Paper, Political Economy Research Institute (PERI), 106.

Pesaran, M. H., Shin, Y. C., \& Smith, R. (2001). Bounds testing approaches to the analysis of level relationships. Journal of Applied Econometrics, 16, 289-326. http://dx.doi.org/10.1002/jae.616

Phillips, P. C. B. (1988). Regression theory for near-integrated time series. Econometrica, 56, 1021-1043. http://dx.doi.org/10.2307/1911357

Sargent, T. J. (1993). Bounded Rationality in Macroeconomics. Oxford: Oxford University Press.

Servén, L. (1998). Macroeconomic Uncertainty and Private Investment in LDCs: An Empirical Investigation.

Tobin, J. (1969). A General Equilibrium Approach to Monetary Theory. Journal of Money, Credit, and Banking, 1, 15-29. http://dx.doi.org/10.2307/1991374

Turrini, A. (2004). Public Investment and the EU Fiscal Framework. European Commission, Directorate-General for Economic and Financial Affairs, Economic Papers, 202.

Välilä, T., \& Mehrotra, A. (2005). Evolution and Determinants of Public Investment in Europe. European Investment Bank, Economic and Financial Report 2005/01. 


\section{Notes}

Note 1 . To be reviewed in subsequent sections.

Note 2. Often precipitated by stagnant economic performance.

\section{Copyrights}

Copyright for this article is retained by the author(s), with first publication rights granted to the journal.

This is an open-access article distributed under the terms and conditions of the Creative Commons Attribution license (http://creativecommons.org/licenses/by/3.0/). 